\title{
O PROCESSO DE LETRAMENTO DIGITAL EM UMA TURMA DO 5은 ANO DO ENSINO FUNDAMENTAL
}

\section{ARTIGO ORIGINAL}

FIGUEIREDO, Ângela Dos Santos ${ }^{1}$

SANTOS, Rubivaldo Ramos Dos ${ }^{2}$

SIMPLICIO, Clebson Dos Santos ${ }^{3}$

FIGUEIREDO, Ângela Dos Santos. SANTOS, Rubivaldo Ramos Dos. SIMPLICIO, Clebson Dos Santos. 0 processo de letramento digital em uma turma do $5^{\circ}$ ano do ensino fundamental. Revista Científica Multidisciplinar Núcleo do Conhecimento. Ano 04, Ed. 12, Vol. 03, pp. 44-52. Dezembro de 2019. ISSN: 2448-0959, Link de acesso: https://www.nucleodoconhecimento.com.br/educacao/letramento-digital

\section{RESUMO}

Com a contribuição de Soares (1999), Moraes e Albuquerque (2007), Moreira (2012) e outros, este artigo traz de forma concisa o que foi realizado durante o processo in lócus, em uma turma do $5^{\circ}$ ano do ensino fundamental, com o objetivo central de investigar como se dá o processo de aprendizado na informática e da forma de como os alunos da referida turma enxergam o mundo digital que o cercam nesse mundo

\footnotetext{
${ }^{1}$ Especialista Em Pedagogia Escolar (UNINTER/IBEPEX); Licenciada Em Informática (IFAP).

${ }^{2}$ Especialista Em Pedagogia Escolar; Especialista Em Administração Escolar E Orientação Educacional; Especialista Em Direito Educacional; Licenciado Em Informática E Licenciado Em História.

${ }^{3}$ Especialista Em Mídias Na Educação (UNIFAP); Especialista Em Educação A Distância (SENAC/AP); Licenciado Em Informática (IFAP) E Tecnólogo Em Informática Educativa (FACULDADE SEAMA).
} 
globalizado. O estudo investiga como se dá o processo de Letramento Digital nesses alunos e especificamente dessa turma, ou seja, busca-se através desse trabalho de investigação, respostas para esse questionamento. Essa turma apresentou um percentual bastante positivo, quanto ao elemento de investigação. Notou-se que os alunos estavam em diferentes estágios em relação ao conhecimento em informática, uns com conhecimentos mais abrangentes que outros, no entanto todos já conheciam a base do conceito, de forma empírica, a introdução digital, elementos importantíssimos para a análise final desta pesquisa.

Palavras-chave: Ensino aprendizagem, informática, letramento digital, investigação.

\section{INTRODUÇÃO}

O presente artigo busca através do estudo e investigação à cerca da temática que discute o letramento digital, utilizando a Informática Educativa como proposta metodológica com a utilização do computador e internet para fins de intervir no processo de letramento. O referido trabalho buscou respostas para a seguinte indagação: como se dá o processo de letramento digital nos alunos da turma do $5^{\circ}$ ano da escola de Ensino fundamental Magalhães Barata do município de Chaves-PA no aprendizado da informática?

Através de pesquisa, realizada no estágio supervisionado, buscou-se respostas para essa indagação que nos move nessa investigação e nesse contexto escolar para fins de fomentar um processo de intervenção pedagógica de maneira mais abrangente a partir dos resultados dessa pesquisa.

Dentro dos novos paradigmas, o letramento surge como um processo pedagógico que revigora o conceito de aprendizado dentro do contexto atual do processo educativo e nas relações de ensino-aprendizagem. Para Soares (1999), letramento é uma nova perspectiva sobre a prática social da escrita, ou seja, um sujeito letrado para a autora é um sujeito capaz de compreender o contexto social em que ele está inserido.

Ainda segundo Soares (1999. p.24): 
... uma última inferência que se pode tirar do conceito de letramento é que um indivíduo pode não saber ler e escrever, isto é, ser analfabeto, mas ser, de certa forma, letrado... (atribuindo a este adjetivo sentido vinculado a letramento).

Dessa forma, mesmo o indivíduo adulto analfabeto, ele consegue abstrair uma leitura de mundo de acordo com as relações que ele estabelece no seu cotidiano.

Nesse sentido, a investigação focou no analfabeto digital, ou seja, naquele indivíduo (alunos/as) que não adquiriram a habilidade do aprendizado digital e não necessariamente nos analfabetos clássicos e com o objetivo central de identificar o desempenho dos alunos (as) do $5^{\circ}$ ano, no âmbito do letramento com a utilização da informática, como processo facilitador nesse contexto.

Este artigo traz três momentos de descrição, o primeiro momento faz um breve resumo de Letramento em seu contexto mais amplo, o segundo momento; faz referência a pesquisa realizada no estágio supervisionado que investigou o processo de Letramento digital de uma turma do $5^{\circ}$ ano do ensino fundamental e 0 terceiro momento; faz as considerações fundamentadas no resultado parcial do que foi investigado in Lócus.

Este artigo também contém: questionário dialogado e fotos que registraram os momentos principais das atividades realizadas com os alunos(as) tanto em sala de aula como no laboratório de informática. As imagens das crianças, neste registrado, estão resguardados com a autorização dos pais e responsáveis.

\section{DESENVOLVIMENTO}

\subsection{CONTEXTUALIZANDO SOBRE LETRAMENTO}

O letramento surge em 1980, mas somente a partir de 1990, ganhou uma visibilidade maior no cenário educacional brasileiro. Também nessa mesma década começam a surgir diferenças de conceitos, principalmente para Kleiman (1995) e Soares (2002). 
Para Soares, o termo letramento advém de uma tradução mais fiel do inglês Literacy, que significa a condição de se fazer o uso social da leitura e da escrita. O processo chamado letramento traz uma diferença no que se refere a alfabetização, apesar desses processos estarem intimamente ligados um ao outro. A alfabetização é o processo formal de ensinar a ler e a escrever.

Então, sendo assim o Letramento é um "conjunto de práticas que denotam a capacidade de uso de diferentes tipos de material escrito" (MORAIS, ALBUQUERQUE, 2007, P.7).

O processo do letramento acontece na criança a partir do momento de sua relação de convivência com pessoas que fazem uso da língua escrita e esse ambiente possua material escrito como: livros, revistas e jornais por exemplo, ou seja, se o ambiente favorece esse processo, essa criança terá mais facilidade em se relacionar com a escrita, a leitura e se bem orientada, conseguirá atingir com mais sucesso o processo do letramento. Como exemplo desse ambiente facilitador para o processo de aprendizagem e mais especificamente no processo de letramento, que contribua para que se desenvolva a potencialidade de uma criança, e um dos fatores fundamentais para o êxito e sucesso na vida desse indivíduo é o que se encontra em ambientes como o da família, igreja, à escola, o clube e outros.

Particularmente, o ambiente familiar e a escola terão papéis fundamentais no progresso e sucesso dessa criança quanto a processo de letramento. $E$ isso não é apenas o letramento escolar, mas o letramento de mundo, de conhecer e compreender a sua relação com esse mundo em que ele está inserido. Compreender aquilo que se escreve e lê, é um processo que à escola vai direcionar essa criança. Nesse sentido, é muito importante a escola compreender o contexto desse indivíduo e saber que uma criança ao chegar na escola, ela não chega vazia, ela traz uma bagagem de conhecimento empírico, que apesar de não estar sistematizado, não pode ser descartado e sim aproveitado para um melhor direcionamento desse processo de letramento com a mediação do professor (a). 
A necessidade de um indivíduo ser letrado digitalmente surgiu a partir da ideia de que uma fonte digital pode gerar muitas formas de informações de texto, como imagens, sons, etc. Por isso, uma nova forma de alfabetização era necessária com o intuito de dar sentido a essas novas formas de apresentação. Segundo Bawden (2008), outros autores, como Eshet (2002), pensam da mesma forma que Gilster (2006): o letramento digital deve ser mais do que a capacidade de usar fontes digitais por ser uma nova forma de pensamento crítico. (MOREIRA, 2012, p.4)

Todo esse contexto nos remete ao Letramento digital, foco principal deste estudo, que compreende $\mathrm{o}$ indivíduo com a capacidade de responder adequadamente as demandas sociais que envolvem a utilização dos recursos tecnológicos e da escrita no meio digital. Por isso é importante adquirir o processo de Letramento digital, pois vai tratar com um mundo cada vez mais conectado e informatizado.

Para Moreira (2012):

A educação mediada pelas novas tecnologias ainda gera muitos questionamentos na sociedade contemporânea. De um modo geral, algumas dúvidas ainda permeiam a prática docente, com relação ao uso de ferramentas tecnológicas. Apesar de vivermos numa era digital, incentivar os professores a ministrar uma aula mediada pela tecnologia continua sendo uma tarefa árdua, principalmente quando a concepção de aprendizagem é centrada somente no educador. Diante disso, faz-se necessária uma reflexão em torno da educação e das mídias digitais a fim de se agregar competências tecnológicas, tanto na visão educacional quanto à formação dos professores. (MOREIRA, 2012, p. 02)

No ponto de vista de Moreira, a questão da prática docente versus a relação do uso das tecnologias ainda está muito distante de uma relação que realmente flua com naturalidade e com sentido a essa relação de ensino aprendizagem. O mesmo nos diz que, apesar de vivermos num mundo que está completamente tomada por tecnologias e inovações para que o professor possa estar se apossando desse processo e utilizando essas ferramentas ao seu favor facilitando assim a sua prática docente e tornando-a mais interessante do ponto de vista pedagógico. Esse mesmo professor ainda é resistente a essa tecnologia, e isso é possível devido tudo ainda ser muito novo, sempre haverá resistência ao novo, por ser desconhecido e também muitos professores já não tem muita predisposição para aprender. Acham tudo muito difícil, trabalhoso e preferem permanecer nas suas velhas práticas. A importância dos 
docentes também se adequarem ao processo do Letramento digital é outro fator de estudo que precisa ser analisado e aprofundado, por essa razão houve a necessidade de se fazer a menção com objetivo de posterior estudo.

\subsection{O PROCESSO DO ESTÁGIO}

Durante as atividades de estágio, observou-se o contexto da escola e como essa escola está trabalhando a questão do letramento digital com seus alunos, mais especificamente na turma que foi o foco de pesquisa. A escola ainda não possui um olhar que priorize esse processo. A escola também possui muitas dificuldades quando se trata de letramento da língua Portuguesa, ou seja, a escola está fazendo um enfoque que não favorece as necessidades dos seus educandos. A percepção obtida nesses momentos de aplicação do estágio, foi de que, é preciso que a escola busque um ajuste em seu currículo, e enfoque as questões da informática e da tecnologia com mais ênfase nas práticas de sala de aula.

Os alunos que lá estão já possuem bagagem empírica de conhecimento sobre essas tecnologias, de alguma forma esses alunos em seu dia- a -dia de relação com esse meio que vivem, os levam a ter contato com: Telefones, tabletes, laptops e outros. Todo esse contato faz com que eles necessitem tomar posse desse conhecimento mais elaborado e sistematizado que é papel da escola transmitir aos mesmos da forma mais facilitadora possível.

Quando se discute essa temática voltada para a escola como foi o objetivo desse artigo, buscou-se resposta para entender melhor como esse processo está sendo trabalhado em nossas escolas, em especial na turma estudada. E acredita-se, que é preciso que a escola trabalhe a inserção de seus professores ao mundo digital, e essa inclusão poderá ser realizada através dos cursos de formação continuada, oficinas pedagógicas voltadas para a aprendizagem dessas novas tecnologias. Portanto, esse docente poderá tomar posse desse conhecimento e assim, ministrará suas aulas, utilizando desses instrumentos proporcionando aulas mais prazerosas e interessantes. 
Fomentar o uso de novas tecnologias em sala de aula, é preparar e dar mais condições aos alunos de prepará-los para esse mundo globalizado, que não temos mais como estar alheios a esse processo. Viver hoje numa sociedade que está interligada ao mundo e a era digital é acompanhar esse avanço tecnológico e a escola faz parte importante nesse processo. Pois, a escola possui credenciamento e é referência quando se trata de sistematizar conhecimento, aprendizado, formação e orientação para que esses alunos de hoje, continuem na construção e reconstrução da nossa sociedade e seu desenvolvimento.

Os alunos observados durante o estágio, são alunos que nos surpreenderam com o nível de noção sobre o letramento digital, apesar da maioria não dispor em suas casas de computadores ou acesso a cyber e internet por exemplo e nem na escola. Pois, a escola possui um laboratório de informática, porém, não possui equipamentos (computadores) para que esses alunos possam ter acesso. Nesse espaço apresenta apenas dois computadores que são insuficientes para atender a demanda dos alunos. Eles relataram que costumam ter acesso a celulares e que através desses equipamentos adquiriram a habilidade de digitar mensagens e acessar redes sociais por exemplo e pesquisar alguns conteúdos escolares. Mas, a escola realmente está muito longe de oferecer essa assistência pedagógica e inserir esses alunos no mundo digital e consequentemente, trabalhar e sistematizar o letramento digital de maneira mais pedagógica. Inclusive, os professores também não possuem esse acesso dentro do ambiente da escola.

Nesse sentido, é importante enfatizar, quando o ambiente da escola é um ambiente facilitador no processo ensino aprendizagem, 0 ato de aprender acontecerá com mais facilidade e consequentemente, esse ambiente se tornará mais prazeroso. A inserção da informática nas atividades pedagógicas é de fundamental importância para o aprendizado dos alunos. Pois, facilitará ainda mais as suas relações interpessoais e de compreensão do contexto digital que e ele já vive. Não se pode mais fugir desse processo. Onde vamos ou estamos, a tecnologia está presente. Se a escola e o professor são um dos meios que mediam a relação de aprendizagem. Então, a escola e o professor precisam estar ajustados as novas necessidades de seus alunos (as). 
Na rede informacional que nos envolve, misturam-se vários saberes e formas muito diversas de aprender, enquanto nosso sistema educativo ainda se encontra todo organizado em torno da escola e do livro. O que estamos vivendo hoje, segundo Martín-Barbero (2006), é uma transformação nos modos de circulação do saber, que, disperso e fragmentado, circula fora dos lugares sagrados que antes o detinham e das figuras sociais que o geriam. Portanto, a escola está deixando de ser o único lugar da legitimação do saber, o que se constitui em um enorme desafio para o sistema educativo. Diante desse desafio, muitas vezes os docentes adotam uma posição defensiva e às vezes até negativa, no que se refere às mídias e às tecnologias digitais, como se pudessem deter seu impacto e afirmar o lugar da escola e o seu como detentores do saber. E preciso que, perante essa nova ordem das coisas, a escola e seus profissionais não se afastem, mas busquem compreender o que se passa e se disponham a interagir com as novas possibilidades. (FREITAS, 2010, p. 7)

Trabalhar o processo de letramento digital com os nossos alunos, não é só uma necessidade educacional. Mas, uma necessidade de vida. Todos em algum momento de suas vidas irão precisar estar capacitados nesse processo para que possam resolver situações de trabalho ou qualquer outra tarefa que lhes careça conhecimento e entendimento sobre tal. A escola precisa estar ajustada nesse sentido, não temos mais como fugir desse mundo digital e das tarefas que nos são impostas no nosso dia- a- dia. Estar letrado digitalmente requer uma nova roupagem nos currículos escolares e na forma de ensinar, essa mediação do professor para o aluno precisa estar consistente e esse professor precisa ter segurança na utilização dessas ferramentas digitais, para que o processo de letramento aconteça da melhor forma possível. Pois, todo ato de ensinar requer antes de tudo conhecimento sobre aquilo que irá ser transmitido ou ensinado. Não basta apenas o professor ir para um laboratório de informática ou na sua própria sala de aula, sem antes ter adquirido o conhecimento sobre o que irá ensinar. A tecnologia está disponível para nos oferecer recursos cada vez mais sofisticados que com certeza, irá facilitar ainda mais o processo de ensino aprendizagem seja ele qual for.

\section{CONSIDERAÇÕES FINAIS}

Apesar de estarmos em mundo globalizado onde a informática está inserida em quase todos os contextos sociais de alguma forma. Percebemos que a escola ainda coloca 
um abismo nesse processo de inserção dos alunos nesse contexto digital, que deveria ser mais acessível. Por exemplo, durante a pesquisa foi observado que os alunos da turma em tese investigada, possuem um potencial de conhecimento bastante desenvolvido. Porém, a escola não oferece esse suporte. A escola está em déficit com esses alunos quando possui um espaço para que funcione o laboratório de informática, mas não possui equipamentos suficientes para atender esses alunos durante o processo de ensino aprendizagem. A necessidade de investimentos e de um olhar mais profundo para esse déficit, possibilitará novas perspectivas para o desenvolvimento educacional voltada para o aprendizado em informática e a inserção de maneira mais concreta no mundo digital. É importante ressaltar que a escola estudada possui conselho escolar com CNPJ e está apta a receber recursos de programas do governo federal voltada para financiamento para a inclusão digital como, por exemplo, o Programa Educação Conectada criado pelo decreto presidencial 9.204 de 23 de novembro de 2017 e outros que podem ser solicitados pelo PDDE Interativo ou no SIMEC que são ferramentas de apoio à gestão escolar desenvolvida pelo Ministério da Educação. No entanto, a escola tem dificuldades administrativas, de pessoal capacitado para a captação e gerenciamento desses recursos.

A proposição da pesquisa, feita através do estágio, trouxe de maneira mais fiel possível, os dados da realidade desse contexto do processo educacional e assim nos dá a possibilidade de intervir posteriormente de forma mais abrangente na situação detectada. Desta forma, espera-se que essa pesquisa contribua de maneira pedagógica e científica para as nossas escolas e para o processo ensino aprendizagem, principalmente, dentro da abordagem que se propõem a investigar, o Letramento Digital. No sentido de instigar cientificamente a temática em tese para que a partir dos dados coletados possam servir de parâmetros para novos estudos. O processo de investigação realizada através do estágio, in lócus, ajudou a encontrar algumas respostas para o início da investigação sobre o processo de Letramento Digital, como por exemplo, a capacitação do corpo docente, técnico e administrativo da escola, melhorar os espaços e os equipamentos dos LIED's e ter profissionais licenciados na área de informática possibilitará a escola ter o suporte profissional e 
pedagógico para suprir essas deficiências. Desta forma, pretende-se solucionar as problemáticas encontradas na pesquisa em tese para amenizar essas deficiências no processo de letramento não só nesse contexto pesquisado, mas nas demais unidades escolares do município e até mesmo em outras instituições escolares do Brasil, utilizando a informática para esse fim, com a perspectiva de colaborar para o processo educacional.

\section{REFERÊNCIAS}

FREITAS, Maria Teresa. Letramento digital e Formação de professores. Educação e revista. Belo Horizonte-MG,2010. p. 335-352

KLEIMAN, Ângela B. Modelos de letramento e as práticas de alfabetização na escola. In: KLEIMAN, Ângela B. (Org.). Os significados do letramento. Campinas, S.P.:Mercado de Letras, 1995. 294 p. p. 15-61.

MORAIS, Artur Gomes de; ALBUQUERQUE, Eliana Borges Correia de. Alfabetização e letramento. Construir Notícias. Recife, PE, v. 07 n.37, p. 5-29, 2007. MOREIRA, Carla. Letramento digital: Do conceito a prática. Centro Federal de educação tecnológica de Mina Gerais. Uberlândia-MG. 2012.

SOARES, Magda. Novas práticas de leitura e escrita: Letramento na Cibercultura. Edu. Soc. Campinas-SP. VOL. 23, n 81, p. 143-160, 2002. Disponível em http//www.cedes.unicamp.br <acesso março 2018>.

\section{Letramento: Um tema em três gêneros - São Paulo:}

Autêntica, 1999.

Letramento e Alfabetização: as muitas facetas Universidade Federal de Minas Gerais - UFMG: Centro de alfabetização, leitura e escrita, 1998. Disponível em http//www.scielo.br <acesso março 2018>.

Enviado: Junho, 2019. 
Aprovado: Dezembro, 2019. 